\title{
Validation of the Acceptance and Action Questionnaire-II in the general Spanish population
}

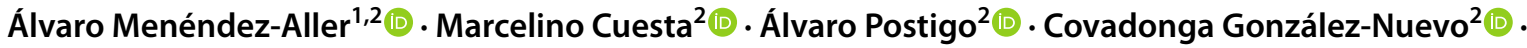 \\ Jaime García-Fernández ${ }^{2}$ (1) . Eduardo García-Cueto ${ }^{2}$ (1)
}

Accepted: 28 October 2021

(C) The Author(s) 2021

\begin{abstract}
Acceptance and Commitment Therapy states that Experiential Avoidance contributes to the development of psychological issues. The Acceptance and Action Questionnaire-II measures Experiential Avoidance. The objective of the current study is to perform a validation of the Acceptance and Action Questionnaire-II in the general Spanish population. A sample of 964 participants from all over Spain was used $(M=43.43$ years; $S D=15.27)$. The psychometric properties of the questionnaire were examined according to Classical Test Theory. In addition, assessments were made of participants' personality, Emotional Intelligence, Anxiety, and Depression, and the influence of sex and age on Experiential Avoidance was examined. The Acceptance and Action Questionnaire-II is a unidimensional instrument, with excellent reliability $(\alpha=.93)$ and adequate evidence of validity. Differences were observed based on sex, with women scoring higher, and based on age, with lower scores in the older age groups. The Acceptance and Action Questionnaire-II is a valid, reliable instrument for use in the general Spanish population.
\end{abstract}

Keywords Experiential Avoidance $\cdot$ AAQ-II $\cdot$ Sex $\cdot$ Age

Over the last 30 years, Acceptance and Commitment Therapy (ACT) has become established as an effective, efficient therapy (Hayes, 2019; Samaan et al., 2020), applicable to a broad range of behavioural problems including anxiety, depression, and schizophrenia (Brown et al., 2020; CotoLesmes et al., 2020). According to Hayes (2019), the beneficial effects of ACT arise from its main objective, the reduction of psychological inflexibility.

Hayes (2019) defined psychological inflexibility as the psychological processes related to a rigid treatment of internal experiences. According to this definition, psychological inflexibility is defined as a trans-diagnostic model which underlies the development of the majority of psychological

Álvaro Postigo

postigoalvaro@uniovi.es

Álvaro Menéndez-Aller

uo252016@uniovi.es

1 Health Research Institute of the Principality of Asturias, Oviedo, Spain

2 Department of Psychology, University of Oviedo, Plaza de Feijoo, Oviedo 33003, Asturias, Spain problems, such as anxiety and depression (Dixon et al., 2020; Monestès et al., 2016).

Of all the components of psychological inflexibility, Experiential Avoidance (EA) is considered to be what most contributes to the development of psychological problems (Dixon et al., 2020; Hayes, 2019). In 2016, Monestès et al. defined EA as the reluctance to remain in contact with private experiences (thoughts, memories, emotions, bodily sensations, etc.) that disturb or cause suffering to the individual. EA is an everyday process, as people tend to avoid negative experiences in their day-to-day lives (Monestès et al., 2016). However, this avoidance may end up being fruitless and the experience may recur, perhaps even with more intensity. This vicious circle may lead to a variety of behavioural problems, from substance abuse to depression and anxiety (Serafini et al., 2016; Sung et al., 2017).

Because of the importance of EA, various instruments have been developed for evaluating it, the most notable of which is the Acceptance and Action Questionnaire-II (AAQ-II; Bond et al., 2011). The AAQ-II is a revision of the original AAQ develop by Hayes et al. (2004). It is a short, 7-point Likert unidimensional scale aimed to measure EA. This instrument has been previously adapted to Spanish in 
a clinical population, having shown good reliability, unidimensionality and adequate evidence of validity (Ruiz et al., 2013). Ruiz et al. (2013) also performed a validation of the AAQ-II in a non-clinical Spanish population, although the sample used was not representative of the general Spanish population as it was primarily composed of university students from one region in the south of Spain.

Using this instrument, it has been possible to study the relationship between EA and other, non-clinical, variables. For example, Cobos-Sánchez et al. (2017) observed that a reduction of psychological inflexibility through training influenced Emotional Intelligence. More specifically, they found that it corresponded to reduced Emotional Attention and increased Emotional Repair and Emotional Clarity.

Previous studies have also examined the relationship between EA and other personality factors, such as the traits from the Big Five model. Steenhaut et al. (2018) looked at the influence of psychological inflexibility on the interaction between personality and psychological wellbeing and whether the effect was different depending on age group. They found that EA moderated the effect between personality and psychological wellbeing independently of age. In addition, they found that Neuroticism was positively correlated with EA, whereas Conscientiousness, Openness to Experience, Extraversion, and Agreeableness were negatively correlated.

Research has also found EA to vary according to sex and age. The results regarding sex, however, vary. Pande (2014) found statistically significant differences by sex, with women scoring higher in EA, while subsequent studies found no statistically significant differences between men and women (Leonard et al., 2020; Rolffs et al., 2016). In terms of age, Landi et al. (2020) found statistically significant differences between young adults and older adults in scores of psychological inflexibility, with young adults scoring higher.

The AAQ-II is one of the most frequently used instruments to measure EA in clinical contexts due to its easiness and shortness (Cobos-Sánchez et al., 2017). Given the importance of the construct it measures (the EA being an influential factor on the development of psychological problems), it is, then, crucial to assess the psychometric properties of the AAQ-II to assure that practitioners are able to provide help to those who need it. Because of this, the assessment of EA in the general Spanish population could help mental health workers to find possible cases at risk. It could also serve as an easy-to-apply research tool for exploring the effects of psychological inflexibility in other nonclinical variables.

Therefore, the general objective of the current study was to validate the instrument in the general Spanish population. To that end, the psychometric properties of the instrument were examined, including reliability, item discrimination indices, dimensionality, and differential item functioning.
Along with the general objective, the study had two additional objectives: Firstly, to examine the relationship between EA and Anxiety, Depression, Emotional Intelligence, and the Big Five personality model; mainly, it is expected that EA will correlate positively with Neuroticism, Emotional Attention, Anxiety and Depression and negatively with the positive aspects of Emotional Intelligence and the rest of the Big Five personality traits. Secondly, to explore the differences in EA scores according to sex and age, and to study whether both variables interact. As seen in previous research, it is predicted that, at least, both sex and age will influence EA separately.

\section{Method}

\section{Participants}

The sample size was determined beforehand. To achieve a maximum sampling error lower than 0.5 with a $95 \%$ confidence level, it was established that the sample size should be comprised of at least 330 participants. After nine months of data collection, the study sample was composed of 982 participants from all over Spain, with a maximum sampling error of 0.28 .18 participants ( $66.7 \%$ men), aged between 19 and 52 years old, $(M=41.1 ; S D=17.52)$ were eliminated afterwards for not having demonstrated the required level of attention (more detail in Procedure).

The final sample was therefore comprised of 964 participants (52.8\% women) of Spanish nationality, aged between 18 and 84 years old $(M=43.43 ; S D=15.27)$.

\section{Instruments}

Acceptance and Action Questionnaire (AAQ-II; Bond et al., 2011). The Spanish adaptation from Ruiz et al. (2013) was used. This is a self-report with 7 Likert-type items with 7 response options, where 1 means "never true" and 7 means "always true". The reliability of the adapted version was $\alpha=0.88$. The scale measures the tendency to shy away from disagreeable experiences (e.g., "I'm afraid of my feelings"), as well as a lack of contact with the present moment due to distress (e.g., "My painful memories prevent me from having a fulfilling life").

Educational-Clinical Anxiety and Depression Questionnaire (CECAD; Lozano et al., 2010). This is a self-report with 50 Likert-type items split into two dimensions: (a) Depression, and (b) Anxiety. With the aim of using a short, reliable test to measure both Anxiety and Depression, ten items were selected from each scale with the best discrimination indices in the manual. All the items were Likert-type, with five response options. 
Trait Mood-Meta Scale (TMMS; Salovey et al., 1995). The Spanish adaptation by Fernández-Berrocal et al. (2004) was used, which is a reduced version of the original, named TMMS-24. This is a self-report scale comprised of 24 items split into three dimensions: (a) Emotional Attention; (b) Emotional Clarity; and (c) Emotional Repair. Each dimension has eight Likert-type items with five response options.

Overall Personality Assessment Scale (OPERAS; VigilColet et al., 2013). This is a self-report with 40 items split into the Big Five traits: (a) Extraversion; (b) Neuroticism; (c) Conscientiousness; (d) Agreeableness; and (e) Openness to Experience. Each trait has 7 Likert-type items with five response options.

Attentional Control Scale. A ten-item scale was used to measure participants' levels of attention paid to the item instructions and to ensure answers were not given at random. Each item had five response options, from 1 to 5 , and participants were asked to choose a specific response (e.g., "Please select option 1").

\section{Procedure}

The test was applied online. The items from the various questionnaires were presented in a random order, including the Attentional Control Scale, with the proviso that items from the same dimension would not be presented consecutively. The test was disseminated following snowball sampling via various social networks. In parallel, a database of emails was used to send a large mailshot. The email sent gave the recipient information about the study and asked for their collaboration, noting that their email addresses would be deleted from the database to ensure confidentiality. Sampling lasted for a total of nine months (from March 2020 to November 2020). None of the participants received any kind of remuneration for participating in the study.

Following data collection, participants who failed to demonstrate the required levels of attention (those with more than two mistakes in the Attentional Control Scale) were removed, as it was considered that the participants showed an inattention bias (Van Sonderen et al., 2013).

Participants' anonymity was carefully preserved, as was confidentiality in line with the relevant data protection legislation (Organic Law 3/2018, $5^{\text {th }}$ December, on Individual Data Protection and the Guarantee of Digital Rights) and the guidelines of the Official College of Psychologists (Official College of Psychologists of the Principality of Asturias, 2015).

\section{Data analysis}

To confirm the fit of AAQ-II to a unidimensional structure, we carried out a confirmatory factor analysis using robust unweighted least squares and a matrix of polychoric correlations. We used two different indices to confirm a good fit of the data (Kline, 2011): CFI, which should be above 0.90, and RMSEA, which should be below 0.08 (Hoyle, 2012).

We used the alpha coefficient to estimate the reliability of the AAQ-II and the other instruments used in the study. To calculate the item discrimination indices for the AAQ-II items, we used the corrected correlation coefficient between each item and the overall score in the test. Items are considered to demonstrate adequate discrimination if this index is over 0.3 .

To assess differential functioning of the AAQ-II items, we first examined the impact of the items by sex. Once we found that all the items demonstrated an impact, we examined whether they exhibited DIF following the procedure proposed by Hidalgo et al. (2005).

We used the Pearson correlation coefficient to study the relationship of AAQ-II with the CECAD, TMMS-24, and OPERAS. To determine whether there were differences in the EA scores by sex, age, and the interaction of those two variables, we performed an ANOVA, using eta squared as a measure of the effect size (Lenhard \& Lenhard, 2016). Once statistically significant differences were observed, the Bonferroni post hoc test was applied.

Data analysis was performed using the IBM SPSS program (Version 24) and MPlus (Version 8) (Muthén \& Muthén, 2017), carrying out every analysis with a confidence level of $95 \%$.

\section{Results}

The characteristics of the final sample are presented in Table 1. As it can be seen, the participants come from all over the Spanish territory.

Next, a confirmatory factor analysis was performed. We found a good fit to a unidimensional structure. The CFI was over $0.90(\mathrm{CFI}=0.996)$ and the RMSEA was below 0.08 $($ RMSEA $=0.064)$.

Table 2 shows the item discrimination indices and factor loadings. It shows that all of the items had indices of discrimination well above the 0.30 criterion, ranging from 0.687 to 0.796 .

In terms of reliability of the instruments used in the study, the AAQ-II $(\alpha=0.93)$ and the scales of Anxiety $(\alpha=0.90)$, Depression $(\alpha=0.95)$, Emotional Attention $(\alpha=0.90)$, Emotional Clarity ( $\alpha=0.91)$, Emotional Repair $(\alpha=0.85)$, Extraversion $(\alpha=0.85)$, and Neuroticism $(\alpha=0.88)$ demonstrated excellent internal consistency (over 0.80) (Hernández et al., 2016). Good internal consistency (over 0.70) was exhibited by the scales for Conscientiousness $(\alpha=0.77)$, Agreeableness $(\alpha=0.74)$, and Openness to Experience $(\alpha=0.79)$. 
Table 1 Distribution of the sample by age, location, and sex

\begin{tabular}{|c|c|c|c|}
\hline \multirow[t]{2}{*}{ Variables } & \multicolumn{2}{|l|}{ Sex } & \multirow[t]{2}{*}{ Total } \\
\hline & Male & Female & \\
\hline \multicolumn{4}{|c|}{ Age groups (years) ${ }^{a}$} \\
\hline $18-29$ & $70(7.3 \%)$ & $174(18.0 \%)$ & $244(25.3 \%)$ \\
\hline $30-45$ & $91(9.4 \%)$ & $138(14.4 \%)$ & $229(23.8 \%)$ \\
\hline $46-54$ & $113(11.7 \%)$ & $104(10.8 \%)$ & $217(22.5 \%)$ \\
\hline 55 and over & $181(18.8 \%)$ & $93(9.6 \%)$ & $274(28.4 \%)$ \\
\hline \multicolumn{4}{|c|}{ Geographical Location $^{b}$} \\
\hline North & $136(14.1 \%)$ & $240(24.9 \%)$ & $376(39.0 \%)$ \\
\hline West & $24(2.5 \%)$ & $22(2.3 \%)$ & $46(4.8 \%)$ \\
\hline East & $82(8.5 \%)$ & $39(4.0 \%)$ & $121(12.5 \%)$ \\
\hline South & $75(7.8 \%)$ & $77(8.0 \%)$ & $152(15.8 \%)$ \\
\hline Center & $138(14.3 \%)$ & $131(13.6 \%)$ & $269(27.9 \%)$ \\
\hline
\end{tabular}

a: The cut-off points were set based on the intervals indicated in García-Madruga (2010)

b: North: Asturias, Cantabria, Basque Country, Navarra; West: Extremadura, Galicia; East: Catalonia, Valencia, Murcia, Balearic Islands; South: Ceuta, Melilla, Canary Islands, Andalucía. Center: Castilla-La Mancha, Castilla-León, Madrid, La Rioja, Aragón

For the differential analysis of the items, first we determined whether the items exhibited an impact. We found statistically significant differences in all the items by sex; however, none of the items met the criteria from Hidalgo et al. (2005) that would have indicated DIF.

Table 3 shows the correlations between the AAQ-II scores and the scores in the other scales used in the study. All the correlations followed the expected patterns as seen in previous studies.

An ANOVA was performed to examine the differences in EA according to sex, age, and the interaction between the two. On confirming that the interaction was not statistically significant $(p=0.186)$, we analyzed the main effects. Table 4 shows the results of the ANOVA, together with the means and standard deviation for each category and the effect size. There were statistically significant differences by sex, with a small effect size, and by age, with a moderate effect size. A
Table 3 Pearson correlations between the AAQ-II and the CECAD, TMMS-24, and OPERAS scales

\begin{tabular}{ll}
\hline Scales & AAQ-II \\
\hline Anxiety & .59 \\
Depression & .77 \\
Emotional Attention & .52 \\
Emotional Clarity & -.38 \\
Emotional Repair & -.35 \\
Extraversion & -.23 \\
Neuroticism & .74 \\
Conscientiousness & -.30 \\
Agreeableness & -.24 \\
Openness to Experience & -.11 \\
\hline
\end{tabular}

All correlations were statistically significant $(p<.001)$

Bonferroni post hoc test was carried out after detecting statistically significant differences in the age group variable. It was observed that the 18-29 and the 55 and over age groups showed statistically significant differences both between themselves and the rest of the age groups.

\section{Discussion}

Since its creation, ACT has been linked to the transdiagnostic movement through the concept of psychological inflexibility, which explains the processes by which psychological problems develop (Dixon et al., 2020; Hayes, 2019; Rolffs et al., 2016). EA has been established as one of the most important components within psychological inflexibility (Dixon et al., 2020; Hayes, 2019). Because of that, it is essential to have instruments that properly measure EA. The AAQ-II (Bond et al., 2011) is one such instrument, which Ruiz et al. (2013) adapted and validated for a clinical Spanish population. They also validated the AAQ-II in a non-clinical population, although the sample they used was composed of university students from a single region in
Table 2 Discrimination indices and factor loadings for the items in the AAQ-II

\begin{tabular}{lll}
\hline Items & $\begin{array}{l}\text { Discrimination } \\
\text { indices }\end{array}$ & Factor loadings \\
\hline $\begin{array}{l}\text { My painful experiences and memories make it difficult for me to live } \\
\text { the life that I would value }\end{array}$ & .763 & 0.792 \\
I'm afraid of my feelings & .722 & 0.772 \\
I worry about not being able to control my worries and feelings & .690 & 0.755 \\
My painful memories prevent me from having a fulfilling life & .765 & 0.807 \\
Emotions cause problems in my life & .796 & 0.869 \\
Most people seem to be handling their lives better than I am & .687 & 0.762 \\
My worries get in the way of my success & .764 & 0.837 \\
\hline
\end{tabular}


Table 4 ANOVA, Mean, Standard Deviation and Eta Squared for the sex and age variables

\begin{tabular}{lllll}
\hline Variable & Category & Mean (SD) & $p$ & $\eta^{2}$ \\
\hline Sex & & & & \\
& Male & $16.6(8.3)$ & $<.001$ & .018 \\
Female & $20.7(9.6)$ & & \\
& & & \\
Age group (years) & $23.67(9.9)$ & $<.001$ & .097 \\
& $18-29$ & $19.27(9.0)$ & & \\
& $30-45$ & $17.71(8.4)$ & & \\
& $46-54$ & $14.86(7.3)$ & & \\
& 55 and over & & & \\
& & &
\end{tabular}

Spain. This means that there might have been a bias in the validation as the sample used was not very representative of the general Spanish population.

The main objective of the present study was to validate the AAQ-II in the general Spanish population with participants from all over the country. The AAQ-II exhibited excellent reliability $(\alpha=0.93)$ (Hernández et al., 2016) and demonstrated adequate discrimination indices (over 0.3). Similarly, it demonstrated a good fit to a unidimensional structure (CFI over 0.9 and RMSEA below 0.08), in line with the structure found in the original study (Bond et al., 2011) and the Spanish adaptation (Ruiz et al., 2013). The correlations indicated evidence of divergent validity with other variables, following the expected pattern (see Table 3). None of the items in the AAQ-II demonstrated differential item functioning by sex. In short, the AAQ-II is a valid, reliable instrument for use in the general Spanish population. It will not only allow detection of individuals at risk of developing psychological problems but it will also allow the influence of EA on non-clinical variables to be studied.

With regard to the correlations with AAQ-II, we found negative correlations between EA and Emotional Clarity and Emotional Repair, along with Extraversion, Openness to Experience, Agreeableness, and Conscientiousness, similar to previous studies (Cobos-Sánchez et al., 2017; Steenhaut et al., 2018). We also found positive correlations between EA and Anxiety and Depression, again in line with previous studies (Ruiz et al., 2013; Sung et al., 2017). The positive correlations between EA and Neuroticism and Emotional Attention need to be examined more deeply.

The relationship between EA and Emotional Attention may be because both refer to constant rumination on emotions and feelings. While EA refers to the tendency to turn away from unpleasant internal experiences (Monestès et al., 2016), Emotional Attention is defined as the level of attention paid to one's emotional state (Salguero et al., 2010). Therefore, it is possible that by attempting to turn away from negative experiences, an individual is paying excessive attention to their internal state.
The relationship between Neuroticism and EA, however, is more complicated. In recent years, the usefulness of the AAQ-II has been criticized by those who have indicated that it in fact measures Neuroticism rather than EA (Rochefort et al., 2018). As can be seen in Table 3, the two variables are strongly correlated, thus high scores in Neuroticism are generally accompanied by high scores in EA. However, ACT posits that EA is theoretically different to Neuroticism (Hayes et al., 1999). EA refers to the tendency to avoid unpleasant experiences (Monestès et al., 2016), whereas Neuroticism is defined as a tendency to experience negative emotions and feelings (Vigil-Colet et al., 2013). In other words, EA refers to a way of relating to unpleasant experiences while Neuroticism refers to the frequency of those experiences. Although the two concepts are related, the main objective of ACT is to reduce EA without the need to eliminate the unpleasant experiences (Hayes, 2019). To put it another way, it suggests that someone with a high score in Neuroticism may exhibit low scores in EA. This can be seen in the current study. When the correlation between the two variables $(r=0.74)$ is squared, it can be seen that they only share $54.7 \%$ of the common variance, meaning $45.3 \%$ of the variance in EA is not related to Neuroticism. So, it is possible that there are people who have high scores in Neuroticism (who often experience unpleasant internal states) and low scores for EA (meaning they do not turn away from those states). To summarize, the AAQ-II and the OPERAS Neuroticism scale measure two different, albeit closely related, constructs. This means the AAQ-II is a viable research tool, which is consistent with what other authors have reported (Barrett et al., 2019).

With regard to differences in EA scores by sex, Table 4 indicates that there were statistically significant differences, with a small effect size $\left(\eta^{2}=0.018\right)$. Women had higher mean scores than men. Although these results are in line with some previous studies (Landi et al., 2020; Pande, 2014), there are other studies in which no differences were found (Leonard et al., 2020; Rolffs et al., 2016). This means it is important to continue studying the influence of sex on EA.

When it came to age, we found statistically significant differences, with a moderate effect size $\left(\eta^{2}=0.097\right)$. Via the post hoc Bonferroni test, we found differences mainly between the 18-29 year-old group and the $55 \mathrm{~s}$ and over compared to the other age groups. According to the means, the older people were, the lower their EA scores. These results are in line with those from Landi et al. (2020), who found that young adults had scores in various measures that indicated greater psychological inflexibility than older adults. Such improvement with age may be for two reasons.

The first reason is related to the acquisition of better coping strategies in the face of unpleasant experiences as people get older. Kelly and Mezuk (2017) found that being older 
was a predictor of remission in diagnoses of depression and anxiety. Similarly, Mahlo and Windsor (2020) found that older adults scored higher in Mindfulness and various components of psychological flexibility, which have been shown to be beneficial against anxiety, for example (John-Lothes et al., 2021). These results are consistent with studies which have shown that, over the long term, at least $50 \%$ of diagnoses of depression and anxiety abate (Eaton et al., 2008; Yonkers et al., 2003). In summary, it is possible that, over time, people learn new coping strategies that tend towards psychological flexibility.

The second reason is the socioeconomic changes that have occurred during the twenty-first century. In recent years, resistance to psychological wellbeing has diminished and the demand for methods to avoid that discomfort, to experientially avoid it, has increased (Pérez-Álvarez et al., 2018). This is evident in the overmedication of psychological disorders and the proliferation of pseudotherapies and self-help guides (Maestro et al., 2017; Pérez-Álvarez et al., 2018). In a nutshell, younger generations have been brought up in a context in which they have been advised to turn away from unpleasant experiences, while older generations grew up in a culture that was more focused on resisting psychological unpleasantness (Maestro et al., 2017; Pavón-Cuéllar, 2017). This, together with the protective effect of the passage of time, may explain why the 18-29 age group scored higher in EA than the older age groups.

EA is a common psychological process that, if taken to its extreme, could result in different psychological problems (Monestès et al., 2016). It is therefore a process that has a great impact in mental health (Hayes, 2019). Thus, the current paper could serve as an argument for the exploration of transdiagnostic processes in the general population (in this case, EA). The current validation of the AAQ-II, a short, easy-to-apply scale, in a non-clinical Spanish population shows that the AAQ-II could help practitioners detect possible at-risk cases. It could also serve as a steppingstone into the research of the impact of EA in other psychological processes, such as personality (Steenhaut et al., 2018), humor (Pande, 2014), suicide behavior (De Berardis et al., 2018)...

Finally, it is important to note that this study does have some limitations. Mainly the lack of a clinical sample. Although the main objective was the validation of the AAQII for the general Spanish population, the test was created to use in a clinical population. This limits the findings of the paper as the results in the general Spanish population cannot be compared to a clinical context, thus making it difficult to establish a clear cut-off point to assess the risk of developing a psychological problem in the future. Therefore, it would be advisable for future studies to replicate the present study using a clinical population. Such studies may also determine the measurement invariance between these populations, in line with what has been done with other psychological variables (Postigo et al., 2021), in order to see if such comparison is viable.

Funding Open Access funding provided thanks to the CRUE-CSIC agreement with Springer Nature.

Availability of data and material The datasets analyzed during the current study are not publicly available due to privacy issues related to the participants but are available from the corresponding author on reasonable request.

Code availability Not applicable.

\section{Declarations}

Ethics approval The study was not explicitly reviewed by an Ethics Committee, given that this is not required by the University of Oviedo, nor by the national guidelines established in the Code of Ethics of the Spanish Psychological Association. There are several reasons why an explicit approval by an Ethics Committee was not necessary: the participants evaluated were adults, the evaluation was voluntarily accepted, that is, an implicit informed consent is assumed, and the data is treated anonymously and confidentially. In addition, all the recommendations established in ISO-10667 Standard for the evaluation of people were strictly followed.

The whole evaluation process and the use of the measuring instruments were carried out always following the Deontological Code of the Spanish Psychological Association (2015), as well as the International Test Commission Guidelines for Test Use (2013).

Conflicts of interest The authors have no conflicts of interest to declare that are relevant to the content of this article.

Open Access This article is licensed under a Creative Commons Attribution 4.0 International License, which permits use, sharing, adaptation, distribution and reproduction in any medium or format, as long as you give appropriate credit to the original author(s) and the source, provide a link to the Creative Commons licence, and indicate if changes were made. The images or other third party material in this article are included in the article's Creative Commons licence, unless indicated otherwise in a credit line to the material. If material is not included in the article's Creative Commons licence and your intended use is not permitted by statutory regulation or exceeds the permitted use, you will need to obtain permission directly from the copyright holder. To view a copy of this licence, visit http://creativecommons.org/licenses/by/4.0/.

\section{References}

Barrett, K., O’Connor, M., \& McHugh, L. (2019). A systematic review of values-based psychometric tools within Acceptance and Commitment Therapy (ACT). The Psychological Record, 69, 457-485. https://doi.org/10.1007/s40732-019-00352-7

Bond, F. W., Hayes, S. C., Baer, R. A., Carpenter, K. M., Guenole, N., Orcutt, H. K., Waltz, T., \& Zettle, R. D. (2011). Preliminary psychometric properties of the Acceptance and Action Questionnaire-II: A revised measure of psychological inflexibility and experiential avoidance. Behavior Therapy, 42(4), 676-688. https:// doi.org/10.1016/j.beth.2011.03.007 
Brown, E., Shrestha, M., \& Gray, R. (2020). The safety and efficacy of Acceptance and Commitment therapy against psychotic symptomatology: A systematic review and meta-analysis. Revista Brasileira de Psiquiatria, S1516-44462020005024207.https://doi.org/ 10.1590/1516-4446-2020-0948

Cobos-Sánchez, L., Flujas-Contreras, J. M., \& Gómez-Becerra, I. (2017). Intervención en flexibilidad psicológica como competencia emocional en adolescentes: Una serie de casos [Intervention in psychological flexibility as emotional competence in adolescents: A case series]. Revista De Psicología Clínica Con Niños y Adolescentes, 4(2), 135-141.

Colegio Oficial de Psicólogos del Principado de Asturias (2015). Código deontológico del Colegio Oficial de Psicólogos del Principado de Asturias [Code of ethics of the Official College of Psychologists of the Principality of Asturias]. http://www.copasturias.org/@ ASThiar_JUN/uploads/deonto/CodigoDeontolog ico-COPPA-2015.pdf

Coto-Lesmes, R., Fernández-Rodríguez, C., \& González-Fernández, S. (2020). Acceptance and Commitment Therapy in group format for anxiety and depression. A systematic review. Journal of Affective Disorders, 263, 107-120. https://doi.org/10.1016/j. jad.2019.11.154

De Berardis, D., Fornaro, M., Valchera, A., Cavuto, M., Perna, G., Di Nicola, M., Serafini, G., Carano, A., Pompili, M., Vellante, F., Orsolini, L., Fiengo, A., Ventriglio, A., Yong-Ku, K., Martinotti, G., Giannantonio, M. D., \& Tomasetti, C. (2018). Eradicating suicide at its roots: Preclinical bases and clinical evidence of the efficacy of ketamine in the treatment of suicidal behaviors. International Journal of Molecular Sciences, 19(10), 2888. https://doi.org/10.3390/ijms 19102888

Dixon, M. R., Hayes, S. C., Stanley, C., Law, S., \& al-Nasser, T. (2020). Is Acceptance and Commitment Training or Therapy (ACT) a method that applied behavior analysts can and should use? The Psychological Record, 70, 559-579. https://doi.org/ 10.1007/s40732-020-00436-9

Eaton, W. W., Shao, H., Nestadt, G., Lee, H. B., Bienvenu, O. J., \& Zandi, P. (2008). Population-based study of first onset and chronicity in major depressive disorder. Archives of General Psychiatry, 65(5), 513-520. https://doi.org/10.1001/archpsyc. 65.5.513

Fernández-Berrocal, P., Extremera, N., \& Ramos, N. (2004). Validity and reliability of the Spanish modified version of the Trait MetaMood Scale. Psychological Reports, 94(3), 751-755. https://doi. org/10.2466/pr0.94.3.751-755

García-Madruga, J. A. (2010). Psicología del desarrollo I [Developmental psychology I]. UNED.

Hayes, S. C. (2019). Acceptance and Commitment Therapy: Towards a unified model of behavior change. World Psychiatry, 18(2), 226-227. https://doi.org/10.1002/wps.20626

Hayes, S. C., Strosahl, K. D., \& Wilson, K. G. (1999). Acceptance and Commitment Therapy: An experiential approach to behavior change. Guilford Press.

Hayes, S. C., Strosahl, K., Wilson, K. G., Bissett, R. T., Pistorello, J., Toarmino, D., Polusny, M. A., Dykstra, T. A., Batten, S. V., Bergan, J., Stewart, S. H., Zvolensky, M. J., Eifert, G. H., Bond, F. W., Forsyth, J. P., Karekla, M., \& McCurry, S. M. (2004). Measuring Experiential Avoidance: A preliminary test of a working model. The Psychological Record, 54(4), 553-578. https://doi.org/10. 1007/BF03395492

Hernández, A., Ponsoda, V., Muñiz, J., Prieto, G., \& Elosua, P. (2016). Revisión del modelo para evaluar la calidad de los tests utilizados en España [Review of the model to assess the quality of the tests used in Spain]. Papeles Del Psicólogo, 37(3), 192-197.

Hidalgo, M. D., Gómez-Benito, J., \& Padilla-García, J. L. (2005). Regresión logística: Alternativas de análisis en la detección del funcionamiento diferencial del ítem [Logistic regression: Analysis alternatives in detecting item's differential functioning]. Psicothema, 17(3), 509-515.

Hoyle, R. H. (2012). Structural equation modeling. The Guilford Press. John-Lothes, I., Mochrie, K., Wilson, M., \& Hakan, R. (2021). The effect of DBT-informed mindfulness skills (what and how skills) and mindfulness-based stress reduction practices on test anxiety in college students: A mixed design study. Current Psychology, 40, 2764-2777. https://doi.org/10.1007/s12144-019-00207-y

Kelly, K. M., \& Mezuk, B. (2017). Predictors of remission from generalized anxiety disorder and major depressive disorder. Journal of Affective Disorders, 208, 467-474. https://doi.org/10.1016/j. jad.2016.10.042

Kline, R. B. (2011). Principles and practice of structural equation modeling. The Guilford Press.

Landi, G., Pakenham, K. I., Boccolini, G., Grandi, Si., \& Tossani, E. (2020). Health anxiety and mental health outcome during COVID19 lockdown in Italy: The mediating and moderating roles of psychological flexibility. Frontiers in Psychology, 11.https://doi.org/ 10.3389/fpsyg.2020.02195

Lenhard, W., \& Lenhard, A. (2016). Calculation of effect sizes. Psychometrica. https://www.psychometrica.de/effect_size.html.

Leonard, K. A., Ellis, R. A., \& Orcutt, H. K. (2020). Experiential avoidance as a mediator in the relationship between shame and posttraumatic stress disorder: The effect of gender. Psychological Trauma: Theory, Research, Practice, and Policy, 12(6), 651-658. https://doi.org/10.1037/tra0000601

Ley Orgánica 3/2018, de 5 de diciembre, de Protección de Datos Personales y garantía de los derechos digitales [Organic Law 3/2018, of December 5, on Protection of Personal Data and guarantee of digital rights]. (2018). Boletín Oficial del Estado, 294, sec. I, de 6 de diciembre de 2018, 119788 a 119857 . https://www.boe.es/ eli/es/lo/2018/12/05/3/dof/spa/pdf

Lozano, L., García-Cueto, E. \& Lozano, L. M. (2010). Cuestionario Educativo-Clínico: Ansiedad y Depresión (CECAD) [EducationalClinical Questionnaire: Anxiety and Depression]. TEA Ediciones.

Maestro, A., González Duro, E., Rendueles, G. O., \& Fernández-Liria, A. (2017). Salud mental y capitalismo [Mental health and capitalism]. CISMA.

Mahlo, L., \& Windsor, T. D. (2020). Older and more mindful? Age differences in mindfulness components and well-being. Aging \& Mental Health, 1-12.https://doi.org/10.1080/13607863.2020. 1734915

Monestès, J. L., Karekla, M., Nele, J., Michaelides, M. P., Hooper, N., Kleen, M., Ruiz, F. J., Miselli, G., Presti, G., Luciano, C., Villatte, M., Bond, F. W., Kishita, N., \& Hayes, S. C. (2016). Experiential Avoidance as a common psychological process in European cultures. European Journal of Psychological Assessment, 34, 247-257. https://doi.org/10.1027/1015-5759/a000327

Muthén, L. K., \& Muthén, B. O. (2017). Mplus (Version 8). [Computer Software]. Muthén \& Muthén.

Pande, N. (2014). Effect of sense of humour on positive capacities: An empirical inquiry into psychological aspects. Global Journal of Finance and Management, 6(4), 385-390.

Pavón-Cuéllar, D. (2017). Subjetividad y psicología en el capitalismo neoliberal [Subjectivity and psychology in neoliberal capitalism]. Psicologia Política, 17(40), 589-607.

Pérez-Álvarez, M., Sánchez, J. C., \& Cabanas, E. (2018). La vida real en tiempos de la felicidad: Crítica de la psicología (y de la ideología) positiva [Real life in times of happiness: A critique of positive psychology and ideology]. Alianza Editorial.

Postigo, Á., García-Cueto, E., Muñiz, J., González-Nuevo, C., \& Cuesta, M. (2021). Measurement invariance of entrepreneurial personality in relation to sex, age, and self-employment. Current Psychology. https://doi.org/10.1007/s12144-021-01685-9

Rochefort, C., Baldwin, A. S., \& Chmielewski, M. (2018). Experiential avoidance: An examination of the construct validity of the 
AAQ-II and MEAQ. Behavior Therapy. https://doi.org/10.1016/j. beth.2017.08.008

Rolffs, J. L., Rogge, R. D., \& Wilson, K. G. (2016). Disentangling components of flexibility via the Hexaflex Model: Development and validation of the Multidimensional Psychological Flexibility Inventory (MPFI). Assessment, 25(4), 458-482. https://doi.org/ $10.1177 / 1073191116645905$

Ruiz, F. J., Langer Herrera, A. I., Luciano, C., Cangas, A. J., \& Beltrán, I. (2013). Measuring experiential avoidance and psychological inflexibility: The Spanish version of the Acceptance and Action Questionnaire-II. Psicothema, 25(1), 123-129. https://doi.org/10. 7334/psicothema2011.239

Salguero, J. M., Fernández-Berrocal, P., Balluerka, N., \& Aritzeta, A. (2010). Measuring perceived emotional intelligence in the adolescent population: Psychometric properties of the Trait Meta-Mood Scale. Social Behavior and Personality: An International Journal, 38(9), 1197-1209. https://doi.org/10.2224/sbp.2010.38.9.1197

Salovey, P., Mayer, J. D., Goldman, S., Turvey, C., \& Palfai, T. (1995). Emotional attention, clarity, and repair: Exploring emotional intelligence using the Trait Meta-Mood Scale. In J. W. Pennebaker (Ed.), Emotion, disclosure, and health (pp. 125-154). American Psychological Association.

Samaan, M., Diefenbacher, A., Schade, C., Dambacher, C., Pontow, I. M., Pakenham, K., \& Fydrich, T. (2020). A clinical effectiveness trial comparing ACT and CBT for inpatients with depressive and mixed mental disorders. Psychotherapy Research, 1-14.https:// doi.org/10.1080/10503307.2020.1802080

Serafini, G., Gonda, X., Pompili, M., Rihmer, Z., Amore, M., \& EngelYeger, B. (2016). The relationship between sensory processing patterns, alexithymia, traumatic childhood experiences, and quality of life among patients with unipolar and bipolar disorders. Child Abuse \& Neglect, 62, 39-50. https://doi.org/10.1016/j. chiabu.2016.09.013

Steenhaut, P., Rossi, G., Demeyer, I., \& De Raedt, R. (2018). How is personality related to well-being in older and younger adults? The role of psychological flexibility. International Psychogeriatrics, 1-11.https://doi.org/10.1017/s1041610218001904

Sung, G., Park, Y., Choi, T. K., \& Park, S. W. (2017). Implicit theories and depression in clinical and non-clinical samples: The mediating role of experiential avoidance. Current Psychology, 39, 68-73. https://doi.org/10.1007/s12144-017-9736-z

Van Sonderen, E., Sanderman, R., \& Coyne, J. C. (2013). Correction: Ineffectiveness of reverse wording of questionnaire items: Let's learn from cows in the rain. PLoS ONE, 8(9). https://doi.org/10. 1371/annotation/af78b324-7b44-4f89-b932-e851fe04a8e5

Vigil-Colet, A., Morales-Vives, F., Camps, E., Tous, J., \& LorenzoSeva, L. (2013). Development and validation of the Overall Personality Assessment Scale (OPERAS). Psicothema, 25(1), 100-106. https://doi.org/10.7334/psicothema2011.411

Yonkers, K. A., Bruce, S. E., Dyck, I. R., \& Keller, M. B. (2003). Chronicity, relapse, and illness-course of panic disorder, social phobia, and generalized anxiety disorder: Findings in men and women from 8 years of follow-up. Depression and Anxiety, 17(3), 173-179. https://doi.org/10.1002/da.10106

Publisher's note Springer Nature remains neutral with regard to jurisdictional claims in published maps and institutional affiliations. 